\title{
Post-critical SsPmp and its Applications to Virtual Deep Seismic Sounding 2. 1D Imaging of the Crust/Mantle and Joint Constraints with Receiver Function
}

\author{
Tianze Liu' ${ }^{1}$ (tianze@stanford.edu), Simon L. Klemperer ${ }^{1}$, Gabriel Ferragut ${ }^{2,3}$, Chunquan Yu ${ }^{4,5}$ \\ 1. Department of Geophysics, Stanford University \\ 2. Department of Geosciences, North Dakota State University \\ 3. Department of Earth Sciences, University of Oregon \\ 4. Seismological Laboratory, California Institute of Technology \\ 5. Department of Earth and Space Sciences, Southern University of Science and Technology
}

\begin{abstract}
Virtual Deep Seismic Sounding (VDSS) has recently emerged as a novel method to image the crust-mantle-boundary (CMB) and potentially other lithospheric boundaries. In Liu et al., 2018 ("Part 1"), we showed that the arrival time and waveform of post-critical SsPmp, the post-critical reflection phase at the CMB used in VDSS, is sensitive to multiple attributes of the crust and upper mantle. Here, we present a synthesis on the methodology of deriving Moho depth, crustal average $V_{p}$ and uppermost mantle $V_{p}$ from single-station observations of postcritical SsPmp under an 1D assumption. We first verify our methods on synthetic examples and then substantiate it with a case study using data collected by the Yellowknife and POLARIS array in SW Slave Province, which shows good agreement between crustal and upper-mantle properties derived with VDSS and the ones given by previous studies using active source experiments and conventional P receiver functions (PRF). Moreover, we show that PRF-VDSS joint analysis is capable of placing tighter constraint on average crustal composition, which cannot be achieved with either method alone. We demonstrate with our PRF-VDSS joint analysis that the SW Slave Province, Canada has an intermediate crust composition, which likely indicates a Neoarchean age.
\end{abstract}

\section{Introduction}

In recent years, Virtual Deep Seismic Sounding (VDSS) has emerged as a novel method to image the crust-mantle boundary (CMB) and has been successfully applied to multiple datasets from different areas (e.g. Kang et al., 2016; Parker et al., 2016; Tseng et al., 2009; Yu et al., 2012, 2016). SsPmp, the seismic phase used in VDSS, originates when upcoming teleseismic $\mathrm{S}$ waves convert to down-going $\mathrm{P}$ waves at the free surface (the virtual source), which then undergo post-critical reflection at or within the CMB and finally reach the receiver (Fig. 1c). 
(Here we use $C M B$ to denote the boundary or geological transition from crust to mantle, whether abrupt or a "velocity-gradient zone" spanning many kilometers; and Moho to denote a seismological inference about this transition, typically given as a single depth.) The arrival time of $S s P m p$ relative to the direct $\mathrm{S}$ arrival (or $S s$ ), hereafter $T_{V D S S}$, is used to estimate the Moho depth at the reflection point, commonly assumed to be the midpoint between the virtual source and receiver. Because VDSS uses teleseismic events, the incident S wave is usually approximated as a plane wave with constant ray parameter. To enable post-critical reflection of SsPmp at the CMB, appropriate epicentral distances are $\sim 30-50^{\circ}$ (Yu et al., 2016), corresponding to ray parameter $p=\sim 0.1256-0.1409 \mathrm{~s} / \mathrm{km}$ for a focal depth of $0 \mathrm{~km}(1 / p=\sim 7.10-7.96 \mathrm{~km} / \mathrm{s})$ (Liu et al., 2018), and slightly smaller $p$ for larger focal depths. Due to post-critical reflection at the CMB, SsPmp usually has amplitude comparable to $S s$ (Fig. 1b), making it possible to construct a seismic profile with a single event recorded by an array. Because SSPmp undergoes post-critical reflection at the CMB, its phase is changed relative to $S s$ (e.g. Aki and Richards, 1980) (Fig. 1b; hereafter referred to as phase shift for simplicity and denoted $\Phi_{V D S S}$ ), making it difficult to directly pick $T_{V D S S}$ from raw records. Previous studies (e.g. Tian et al., 2015; Tseng et al., 2009; Yu et al., 2016) have used 1D waveform fitting to measure $T_{V D S S}$, and then found the trade-off relation between average crustal $V_{p}{ }^{a v}$ and thickness $H$ using the equation:

$$
T_{V D S S}=2 H \sqrt{\frac{1}{V_{p}^{a v 2}}-p^{2}}
$$

where $p$ is the ray parameter of $S s$ and SsPmp. In our previous paper (Liu et al., 2018), using 1D synthetic tests, we found that whereas $T_{V D S S}$ is primarily determined by CMB depth and crustal average $V_{p}, \Phi_{V D S S}$ is sensitive to lower-crustal and uppermost-mantle $V_{p}\left(V_{p}^{l c}\right.$ and $\left.V_{p}^{u m}\right)$, which implies the possibility of constraining $V_{p}^{l c}$ and $V_{p}^{u m}$ with observations of $\Phi_{V D S S}$.

Here, we first show that $T_{V D S S}$ can be estimated by picking peaks on SsPmp envelope functions, which can be used to derive Moho depth. We then present synthetic tests to demonstrate that $V_{p}^{u m}$ can be constrained without a priori knowledge of $V_{p}^{u m}$ using post-critical SsPmp with turning velocity $1 / p$ close to $V_{p}^{u m}$. We finally present a case study using data collected by the Yellowknife and POLARIS array in the SW Slave Province, which shows good agreement between crustal and upper-mantle properties derived by us with VDSS and the ones from previous studies using active-source experiments and our own conventional P receiver functions (PRF). Specifically, our $V_{p}^{u m}$ agrees with $P n$ velocity derived with seismic refraction 
experiments (Hammer et al., 2010), and our VDSS Moho depth matches the Moho depth given by both seismic reflection experiments (Hammer et al., 2010) and our PRF. In addition, we demonstrate that by joint analysis of PRF and VDSS, we can simultaneously estimate average crustal $V_{p}$ and $V_{p} / V_{s}$ ratio, thereby placing tight constraints on average crustal composition.

\section{Synthetic Examples}

\subsection{Measuring $T_{V D S S}$ from Envelope Functions}

When a signal undergoes a phase shift, despite the change of its waveform, its envelope function stays constant (Aki and Richards, 1980a). Therefore, a simple way to account for the phase shift of SSPmp relative to $S_{S}$ while measuring $T_{V D S S}$ is to calculate the time between the peaks on $S s$ and $S s P m p$ envelope functions (Parker et al., 2016). Fig. 2a shows synthetic waveforms calculated using the reflectivity algorithm (Randall, 1989) for the 1D models in Fig. 1 (hereafter "Model \#1") and $0.124 \leq p \leq 0.140 \mathrm{~s} / \mathrm{km}$, after separation into pseudo-P (motion associated with incoming $\mathrm{S}$ waves) and pseudo-S (motion associated with incoming $\mathrm{P}$ waves) components (hereafter referred to as $\mathrm{P}$ and $\mathrm{S}$ for simplicity) with a particle-motion analysis algorithm (Yu et al., 2013) and converting to envelope functions. The shapes of Ss (S component) and $\operatorname{Ss} P m p$ (P component) envelope functions are essentially identical, as the arrivals are only distinguished by a phase shift $\left(\Phi_{V D S S}\right)$, a negligible amplitude change due to post-critical reflection, and a time delay. We then measure $T_{V D S S}$ from these $S s$ and $S s P m p$ envelope functions and convert them to Moho depths using Eq. 1 and the true average crustal $V_{p}$. The estimated Moho depths agree (within $0.1 \mathrm{~km}$ ) with the true CMB depth for all $p$ (Fig. 2b), indicating the robustness of this method. We note that given multiple $S s P m p$ observations with a wide range of ray parameter $p$, as in our example here, we can simultaneously determine Moho depth and crustal average $V_{p}$ (Kang et al., 2016), as shown below in our analysis of observations from the SW Slave Province (see Section 3). Although $T_{V D S S}$ can be robustly estimated from SsPmp envelope functions, when calculating these envelope functions we effectively eliminate the information contained in $\Phi_{V D S S}$ (Fig. 2a), which is sensitive to the structure of the CMB (Liu et al., 2018). Therefore, a more desirable way to analyze $S s P m p$ is to model $T_{V D S S}$ and $\Phi_{V D S S}$ simultaneously.

\subsection{Modeling $T_{V D S S}$ and $\Phi_{V D S S}$ Simultaneously}


In order to measure $T_{V D S S}$ and $\Phi_{V D S S}$ simultaneously, we first generate synthetic SSPmp waveforms for all combinations of $V_{p}$ in the lower crust $\left(V_{p}^{l c}\right)$ and upper mantle $\left(V_{p}^{u m}\right)$ using the reflection coefficient at the Moho (Aki and Richards, 1980b). We then use cross-correlation to align the synthetic SsPmp waveforms with the "observed" data (e.g. the waveforms in Fig. 1b) and compute the normalized misfit (hereafter referred to as misfit for simplicity) between the synthetic and "observed" SsPmp. Before computing the misfit, we normalize the "observed" and synthetic $S s P m p$ by the peak values of their envelope functions so that the effects of amplitude difference are eliminated. The synthetic SsPmp waveform with the minimum misfit determines the best-fit $V_{p}^{l c}$ and $V_{p}^{u m}$, and the best-fit $T_{V D S S}$ is found by picking the peak cross-correlation value between the best-fit synthetic SsPmp and the "observed" one. Note that previous 1D modeling schemes have held $V_{p}^{l c}$ and/or $V_{p}^{u m}$ fixed (Tian et al., 2015; Tseng et al., 2009; Yu et al., 2016). To test this approach, we use the reflectivity method (Randall, 1989) to compute "observed" waveforms and try to recover $T_{V D S S}, V_{p}^{l c}$ and $V_{p}^{u m}$ from them using the method described above.

We first attempt to recover both $V_{p}^{l c}$ and $V_{p}^{u m}$ from the observed $S s P m p$ waveforms. Our “observed" waveforms are computed with Model \#1, a single layer crust with $V_{p}=6.5 \mathrm{~km} / \mathrm{s}$ overlaying a half space with $V_{p}=8.1 \mathrm{~km} / \mathrm{s}$ that represents the upper mantle (Fig. 1a). We assume two different ray parameters $p=0.128$ and $0.136 \mathrm{~s} / \mathrm{km}$ to study the potential effects of ray parameter. After applying our proposed method, the resulting misfits are plotted as functions of $V_{p}^{l c}$ and $V_{p}^{u m}$ (Fig. 3). In the case with $p=0.128 \mathrm{~s} / \mathrm{km}(1 / p=7.81 \mathrm{~km} / \mathrm{s})$, we observe that the misfit depends strongly on $V_{p}^{u m}$ and weakly on $V_{p}^{l c}$, with the misfit contours having small negative slopes (negative trade-off between $V_{p}^{l c}$ and $V_{p}^{u m}$; Fig. 3). In contrast, in the case with $p$ $=0.136 \mathrm{~s} / \mathrm{km}(1 / p=7.35 \mathrm{~km} / \mathrm{s})$, although the trade-off between $V_{p}^{l c}$ and $V_{p}^{u m}$ is still negative, the misfit depends weakly on both $V_{p}^{l c}$ and $V_{p}^{u m}$ (Fig. 3b). [Note that because the observed and synthetic waveforms are not computed in the same way, minor differences exist between them that makes the minimum misfits in both cases non-zero (Fig. 3).] Because fitting SsPmp waveforms is equivalent to fitting $\Phi_{V D S S}$, this behavior of misfit can be understood by considering the dependence of $\Phi_{V D S S}$ on $V_{p}^{l c}$ and $V_{p}^{u m}$. When $1 / p$ is close to $V_{p}^{u m}$, e.g. the case with $p=0.128 \mathrm{~s} / \mathrm{km}\left(1 / p=7.81 \mathrm{~km} / \mathrm{s}\right.$; Fig 3a), $\Phi_{V D S S}$ is primarily controlled by $V_{p}^{u m}$ with only weak dependence on $V_{p}^{l c}$ (Liu et al., 2018). When $1 / p$ is close to neither $V_{p}^{u m}$ nor $V_{p}^{l c}$, e.g. the case with $p=0.136 \mathrm{~s} / \mathrm{km}(1 / p=7.35 \mathrm{k} / \mathrm{s} ;$ Fig $3 \mathrm{~b}), \Phi_{V D S S}$ depends weakly on both $V_{p}^{u m}$ and $V_{p}^{l c}$ 
(Liu et al., 2018). Ideally, when $1 / p$ is close to $V_{p}^{l c}$, misfit will be primarily controlled by $V_{p}^{l c}$ due to the strong dependence of $\Phi_{V D S S}$ on $V_{p}{ }^{l c}$. However, in this case the large $p$ may cause strong pre-critical reflections from intra-crustal interfaces that may interfere with SsPmp and distort its waveform (e.g. Fig. 5 in Liu et al., 2018). Therefore, a more practical way to utilize $\Phi_{V D S S}$ observations is to infer $V_{p}^{u m}$ from $\Phi_{V D S S}$ while assuming a known $V_{p}^{l c}$ in cases with $1 / p$ close to $V_{p}^{u m}$, because in such cases an incorrect $V_{p}^{l c}$ would only have limited effect on estimated $V_{p}^{u m}$ (Fig. 3a).

Fig. 4 shows examples of this strategy of estimating Moho depth and $V_{p}^{u m}$ from SsPmp waveforms while fixing $V_{p}^{l c}$. We use the correct crustal average $V_{p}=6.5 \mathrm{~km} / \mathrm{s}$ in Eq. 1 to convert the measured $T_{V D S S}$ to Moho depth. For $p=0.128 \mathrm{~s} / \mathrm{km}$, when the true $V_{p}^{l c}=6.5 \mathrm{~km} / \mathrm{s}\left(V_{p}^{l c}\right.$ and average crustal $V_{p}$ are the same here because the crust is homogeneous) is assumed, we are able to recover both the CMB depth and $V_{p}^{u m}$ precisely (Fig. 4a). As a result of the precisely recovered $V_{p}^{u m}$ and $V_{p}^{l c}$, the synthetic $S s P m p$ matches the observation almost perfectly (Fig. $4 \mathrm{~b}$ ). For the same "observed" data $(p=0.128 \mathrm{~s} / \mathrm{km})$, when we vary $V_{p}^{l c}$ from the true value to 6.2 and $6.8 \mathrm{~km} / \mathrm{s}$ ( $\sim 5 \%$ perturbation), only $\sim 0.6 \%$ error is introduced to the estimated $V_{p}^{u m}(< \pm 0.05$ $\mathrm{km} / \mathrm{s}$ ), and its effect on estimated Moho depth is negligible (Fig. 4c). The misfit curves for $V_{p}^{l c}=$ $6.2,6.5$ and $6.8 \mathrm{~km} / \mathrm{s}$ have very similar minima, indicating that the synthetics fit the "observed" data equally well for all three cases (Fig. 4d). Because $\Phi_{V D S S}$ is matched precisely in all three cases, the correct $T_{V D S S}$ is found in each case and we are able to give the correct CMB depth despite errors in assumed $V_{p}^{l c}$ (Fig. 4c). To further explore the effects of $p$ on the trade-off between $V_{p}^{l c}$ and $V_{p}^{u m}$, we infer Moho depth and $V_{p}^{u m}$ from "observed" SsPmp waveforms with $p$ $=0.136 \mathrm{~s} / \mathrm{km}$, again assuming $V_{p}^{l c}=6.2,6.5,6.8 \mathrm{~km} / \mathrm{s}$. In this case, a $\sim 5 \%$ perturbation in $V_{p}^{l c}$ causes $\sim 1-2 \%$ error in the estimated $V_{p}^{u m}$, significantly larger than the case with $p=0.128 \mathrm{~s} / \mathrm{km}$, whereas the effect on estimated Moho depth is still negligible due to the precisely matched SsPmp waveforms (Fig. 4e). We also observe that the troughs of the misfit curves are significantly wider for $p=0.136 \mathrm{~s} / \mathrm{km}$ than for $p=0.128 \mathrm{~s} / \mathrm{km}$, indicating poorer constraints on $V_{p}^{u m}$ (Fig. 4f). The above results show that, in a 1D earth, matching $\Phi_{V D S S}$ alone is sufficient to estimate $T_{V D S S}$ and CMB depth precisely, whereas to infer $V_{p}^{u m}$ from $\Phi_{V D S S}$ requires a priori knowledge of $V_{p}^{l c}$. If $V_{p}^{l c}$ is poorly constrained in the study region, it is better to use $S s P m p$ waveforms with $1 / p$ close to $V_{p}^{u m}$ so that an incorrect assumed $V_{p}^{l c}$ causes less error in the estimated $V_{p}^{u m}$. Even in cases with well-constrained $V_{p}^{l c}$, using $S s P m p$ waveforms with $1 / p$ close 
EarthArXiv preprint, in review with Geophysical Journal International

to $V_{p}^{u m}$ is still preferred because the narrower troughs of the misfit curves in such cases would result in better constrained $V_{p}^{u m}$ (smaller uncertainty).

\section{Observations from the SW Slave Province}

The Canadian Shield is one of the Earth's largest cratons in the world. Its longevity and stability imply a lithospheric structure closer to $1 \mathrm{D}$ than in tectonically active areas. The Yellowknife Array was deployed in SW Slave Province, a major component of the Canadian Shield (Fig. 5a,b), in 1962 and was upgraded to digital recording in 1989 (Bostock, 1998). The long deployment time and its location at the core of the Canadian Shield makes it an ideal place to test our proposed method for retrieving and analyzing both $T_{V D S S}$ and $\Phi_{V D S S}$ under 1D assumption. In addition, the SNorCLE component of the Lithoprobe project has accumulated rich material on crustal structure of the study area (e.g. Cook, 2002; Fernández-Viejo et al., 2005; Hammer et al., 2010), providing an unprecedented chance for direct comparison between VDSS and active-source results.

Among all the archived stations of the Yellowknife Array available in the Data Management Center of the Incorporated Research Institutions for Seismology (IRIS), the station YKW3 has the longest archived broadband recording (1994-2014). In addition, Station EDZN of the temporary POLARIS array (Snyder and Bruneton, 2007) was located $\sim 80 \mathrm{~km} \mathrm{NW}$ of YKW3, within $30 \mathrm{~km}$ of Moho reflection points of SsPmp recorded at YKW3 (Fig. 5b), making it appropriate to compare PRF results at EDZN with VDSS results at YKW3, as conversion points of PRFs at Moho depth are typically $<20 \mathrm{~km}$ away from the station. For VDSS analysis at YKW3, we used 56 teleseismic events in the epicentral range $30-60^{\circ}$ with the back-azimuth range of $290-310^{\circ}$. We choose this narrow back-azimuth range to avoid possible complications from lateral variation in lithospheric structure (the Moho reflection points of our selected events are all within $25 \mathrm{~km}$ of each other (Fig. 5b)), while still including plenty of events from the Kamchatka subduction zone with a wide range of ray parameters (Figs. 5a, b). We then remove the instrumental response, apply a bandpass Butterworth filter between $0.05-0.5 \mathrm{~Hz}$, and separate the radial and vertical components of the data to $\mathrm{P}$ and $\mathrm{S}$ components using a particlemotion analysis algorithm (Yu et al., 2013). After separating the data into P and S components, we manually inspect the traces and their particle-motion diagrams to choose 19 events with 
simple $S s$ waveform and significant $\mathrm{P}$ energy following the $\mathrm{S}$ arrival. We then compute the envelope functions of the $\mathrm{P}$ and $\mathrm{S}$ components of the 19 events and select the ones with the ratio between the maxima of $\mathrm{P}$ envelope function and $\mathrm{S}$ envelope function $>0.6$, which further reduce the number of events to 10 . The selected 10 events all have simple $S s$ waveforms and strong $S s P m p$ following the $S s$ arrival (Fig. 5b). When sorted by their ray parameter, the 10 traces show a clear increase of $T_{V D S S}$ (moveout) with decreasing ray parameter (Fig. $5 \mathrm{c}$ ), which can be used to simultaneously constrain the crustal average $V_{p}$ and crustal thickness (Kang et al., 2016). In order to measure $T_{V D S S}$ and $\Phi_{V D S S}$ simultaneously, for each event we use a cosinetapered 20-s window around the $S s$ waveform on the S component as the source wavelet of that event. We then apply phase shifts from $0-360^{\circ}$ to the source wavelet to create synthetic $S s P m p$ waveforms with all possible phase shifts. For each synthetic SsPmp wavelet, we used crosscorrelation to find the best alignment between it and the observed SsPmp. We then normalize both the observed and synthetic SsPmp and compute the misfit between them. The $\Phi_{V D S S}$ of the event is determined as the phase shift that minimizes the misfit between the synthetic and modeled $S_{S} P m p$ (Fig. 5d). We estimate the uncertainty of $T_{V D S S}$ and $\Phi_{V D S S}$ from curvature of the $\Phi_{V D S S}$-misfit function around the best-fit $\Phi_{V D S S}$ (See Supplementary Text 1 and Fig. S1). Here we apply another round of data selection that excludes the events with minimum misfit $>0.4$, because a large misfit implies that the $S S P m p$ of the event cannot be well approximated as phase-shifted from the source time function, which violates our basic assumption. This finally reduces the number of events to 7 . The $T_{V D S S}$ of each event is then found by cross-correlation between the best-fit synthetic SsPmp and the observed SsPmp. For PRF analysis at EDZN, we requested teleseismic $\mathrm{P}$ wave data between $30-90^{\circ}$ from Canadian Hazards Information Service and used the time-domain iterative deconvolution algorithm with a Gaussian bandwidth of 2.5 Hz to compute PRFs (Herrmann, 2013). We manually selected 73 high-quality RFs using the Funclab software package (Porritt and Miller, 2018), which are moveout-corrected to normal incidence for primary $P s$ conversions and stacked (Fig. 6a). We also perform conventional $H-k$ stacking with the selected RFs using the average crustal $V_{p}=6.62 \mathrm{~km} / \mathrm{s}$ (hereafter $V_{p}^{a v}$ ) constrained with VDSS analysis and a phase weight ratio $w_{P s}: w_{P p P m s}: w_{P p S m s}=1: 0.5: 0.5$ (Fig. 6c) (Zhu and Kanamori, 2000).

The arrival time of the Moho Ps in PRF can be expressed as: 
EarthArXiv preprint, in review with Geophysical Journal International

$$
T_{P m s}=H\left(\sqrt{\left(\frac{k}{V_{p}^{a v}}\right)^{2}-p^{2}}-\sqrt{\left(\frac{1}{V_{p}^{a v}}\right)^{2}-p^{2}}\right)
$$

in which $k$ is the crustal average $V_{p} / V_{s}$ ratio. Using $H$ and $V_{p}{ }^{a v}$ derived from $S s P m p$ observations, we can derive $k$ (hereafter $k_{\text {joint }}$ ) from $T_{P_{s}}$. Unlike the conventional $H$ - $k$ stacking method that relies on the Moho multiples (PpPms, PpSms etc.), our proposed method uses only Ps, the most robust phase in PRF observations. To estimate the uncertainty of our $k_{\text {joint }}$, we draw 5000 random samples of $V_{p}{ }^{a v}$ and $H_{V D S S}$ from their joint distribution (Kang et al., 2016) and compute $k_{\text {joint }}$ for each pair. We estimate the uncertainty of our $k_{\text {joint }}$ from the variance of the 5000 randomly simulated $k_{\text {joint }}($ Fig. $6 \mathrm{~b}, \mathrm{c})$. Since $V_{p}{ }^{a v}$ and $k_{\text {joint }}$ together place key constraints on crustal average composition (Christensen, 1996; Christensen and Mooney, 1995), we also compute the joint distribution of $V_{p}^{a v}$ and $k_{\text {joint }}$ (Fig. 8).

Our observed $T_{V D S S}$ clearly decreases with increasing ray parameter, with a typical uncertainty of $\pm 0.3 \mathrm{~s}$ (Fig. 5e). We find the best-fit crustal $V_{p}{ }^{a v}$ and Moho depth $\left(H_{V D S S}\right)$ to be $6.62 \pm 0.20 \mathrm{~km} / \mathrm{s}$ and $37.7 \pm 4.2 \mathrm{~km}$ respectively (Fig. 5e; Kang et al., 2016). Our Moho depth is in good agreement with previous active source reflection results $(\sim 37 \mathrm{~km})$ (Hammer et al., 2010) and is slightly deeper than by within uncertainty of seismic refraction results ( $\sim 31-33$ $\mathrm{km}$ )(Fernández-Viejo et al., 2005; Hammer et al., 2010), whereas our crustal average $V_{p}$ is slightly higher than the value given by active-source refraction studies $(\sim 6.4 \mathrm{~km} / \mathrm{s})$ (FernándezViejo et al., 2005; Hammer et al., 2010). When comparing our VDSS Moho depth $\left(H_{V D S S}\right)$ with the $H-k$ Moho depth $\left(H_{H k}\right)$, we find a close match between them $\left(H_{V D S S}=37.7 \mathrm{~km}\right.$ vs. $H_{H k}=37.3$ km; Fig. 6c). The agreement between $H_{V D S S}$ and $H_{H k}$ not only verifies this result, but also indicates that $6.62 \mathrm{~km} / \mathrm{s}$ is likely a reliable estimation of crustal average $V_{p}$.

Our $\Phi_{V D S S}$ shows a clear decrease with increasing ray parameter, in agreement with our theoretical predictions (Liu et al., 2018). To find the best-fit $V_{p}^{u m}$, we plot theoretical $p$ - $\Phi_{V D S S}$ relations with different $V_{p}^{u m}$ values while assuming $V_{p}^{l c}=6.8 \mathrm{~km} / \mathrm{s}$, the value given by activesource refraction studies (Fig. 5f; Hammer et al., 2010), and compare them with the observed values. The comparison shows that the observations favor $V_{p}^{u m}=8.0-8.1 \mathrm{~km} / \mathrm{s}$, which agrees reasonably well with $P n$ velocity of $\sim 8.2 \mathrm{~km} / \mathrm{s}$ reported by the refraction studies (Fig. 5f) (Fernández-Viejo et al., 2005; Hammer et al., 2010). To test the effects of $V_{p}^{l c}$ on the estimated $V_{p}^{u m}$, we compare the theoretical curves computed by assuming $V_{p}^{l c}=6.6,6.8,7.0 \mathrm{~km} / \mathrm{s}(\sim 3 \%$ 
perturbation; Fig. 7). We observe that for $V_{p}^{l c}=6.5$ and $6.8 \mathrm{~km} / \mathrm{s}$, the theoretical $p$ - $\Phi_{V D S S}$ curves overlap when $p$ is small and gradually diverge as $p$ increases (Fig. 7), but never to the extent that may affect the estimated $V_{p}^{u m}$, especially when the uncertainties of our observed $\Phi_{V D S S}\left(\sim 20^{\circ}\right)$ is considered (Fig. 7). The theoretical $p$ - $\Phi_{V D S S}$ relations are insensitive to assumed $V_{p}^{l c}$ because the reciprocal of ray parameter $(1 / p)$ considered here $(7.5-8.1 \mathrm{~km} / \mathrm{s})$ is significantly higher than the assumed $V_{p}^{l c}$, which makes $\Phi_{V D S S}$ insensitive to $V_{p}^{l c}$ (Liu et al., 2018). In the case of $V_{p}^{l c}=6.6$ $\mathrm{km} / \mathrm{s}(7.0 \mathrm{~km} / \mathrm{s})$, the theoretical $p-\Phi_{V D S S}$ curves are shifted slightly upward (downward) compared to the case with $V_{p}^{l c}=6.8 \mathrm{~km} / \mathrm{s}$, because for a fixed ray parameter, decreasing (increasing) $V_{p}^{l c}$ while fixing $\Phi_{V D S S}$ requires an increase (decrease) in $V_{p}^{u m}$ (negative trade-off between $V_{p}^{l c}$ and $V_{p}^{u m}$; Liu et al., 2018).

We observe clear Moho Ps at $4.24 \mathrm{~s}$ and little energy from intra-crustal convertors on the normal-moveout-stacked PRF of EDZN (Fig. 6a), in contrast to clear interfaces between upper, middle and lower crust shown by active-source refraction results (Hammer et al., 2010). The PRFs plotted as a function of back-azimuth (Fig. S2) are uniform, further supporting our 1D assumption as they show no evidence of dip on the Moho or anisotropy in the crust. Using our $T_{P s}, V_{p}{ }^{a v}$ and $H_{V D S S}$, we find $k_{\text {joint }}=1.745 \pm 0.061$ (Fig. $\left.6 \mathrm{~b}\right)$, which matches $k_{H k}$ very well $\left(k_{\text {joint }}=\right.$ 1.745 vs. $\left.k_{H k}=1.754\right)$. This agreement, together with the close match between $H_{V D S S}$ and $H_{H k}$, demonstrate the robustness of our method.

The joint distribution between $V_{p}^{a v}$ and $k_{\text {joint }}$ shows a clear negative correlation between them (Fig. 8). We also plot $V_{p}$ and $k$ of major crustal rock types measured at $600 \mathrm{MPa}$ (corresponds to mid-crustal depth) and room temperature from Christensen 1996, which shows a positive correlation between $V_{p}$ and $k$ (Fig. 8). We note that temperature effects on both rock $V_{p} / V_{s}$ ratio and $V_{p}$ are small compared to the uncertainties of each rock type (Christensen, 1996; Christensen and Mooney, 1995). As the $\mathrm{SiO}_{2}$ content of the rock increases (more felsic), both the $V_{p} / V_{s}$ ratio and $V_{p}$ of it decreases (Fig. 8). Because our observed $V_{p}-k$ correlation is opposite to the $V_{p}-k$ correlation of laboratory measurements, we could tightly constrain the average crustal composition in our study area as diorite or felsic granulite (Fig. 8).

\section{Discussion}

Post-critical SsPmp has 3 major attributes: $T_{V D S S}, \Phi_{V D S S}$ and $A_{V D S S}$ In $1 \mathrm{D}, A_{V D S S}$ is only affected by near-surface velocity (Liu et al., 2018), whereas $T_{V D S S}$ and $\Phi_{V D S S}$ both contain 
information on crustal and upper-mantle structure. In this paper, we propose methods to retrieve Moho depth, $V_{p}^{a v}$ and $V_{p}^{u m}$ from SsPmp observations under the 1D assumption.

$\Phi_{V D S S}$ is controlled by $V_{p}^{l c}$ and $V_{p}^{u m}$ and can be measured from SsPmp by waveform fitting (Figs. 3 and 4). Due to the trade-off between $V_{p}^{l c}$ and $V_{p}{ }^{u m}$, it is impossible to determine one without knowing the other (Fig. 3). However, we show that when $p$ is small $(1 / p$ close to $\left.V_{p}^{u m}\right), \Phi_{V D S S}$ depends only weakly on $V_{p}^{l c}$, allowing determination of $V_{p}^{u m}$ without a precisely known $V_{p}^{l c}$ (Fig. 3 and 4; Liu et al., 2018). Although $V_{p}^{u m}$ can be derived from a single $S s P m p$ observation (Fig. 4), a combination of $\Phi_{V D S S}$ from multiple $S S P m p$ traces can significantly reduce estimation error (Fig. 5). We note that, when measuring $\Phi_{V D S S}$, it is important to choose only traces with high signal-to-noise ratio, as waveform observables are more sensitive to noise than travel-time measurements. This is especially true when considering the higher noise level of teleseismic S compared to $\mathrm{P}$ wave due to coda waves generated by preceding $\mathrm{P}$ phases that arrive in the same time window. A practical criterion for data quality control is to choose $S s P m p$ traces that can be well-fit with a phase-shifted $S s$ wavelet (Fig. 5). When comparing our derived $V_{p} u m$ with the $P n$ velocity given by active-source refraction experiments (Fernández-Viejo et al., 2005; Hammer et al., 2010), we find our result to be slightly lower $(8.0-8.1 \mathrm{~km} / \mathrm{s}$ vs. $\sim 8.2 \mathrm{~km} / \mathrm{s})$. This discrepancy might be due to the different frequency band of the two methods. The SsPmp observations we use has a center frequency of $\sim 0.25 \mathrm{~Hz}$, much lower than the active-source source data that has a dominant frequency of $\sim 5 \mathrm{~Hz}$ (Fernández-Viejo et al., 2005). The lower frequency SsPmp samples a deeper part of the upper mantle than active-source $P n$, suggesting $V_{p}$ decreasing with depth, consistent with mineral-physics for typical lithosphere conditions (Garber et al., 2018). We caution that the uncertainty of the active-source $P n$ velocity $( \pm 0.1-0.2$ $\mathrm{km} / \mathrm{s}$ ) (Fernández-Viejo et al., 2005) means this conclusion can only be tentative at this time.

$T_{V D S S}$ is controlled by crustal thickness and $V_{p}{ }^{a v}$ and can be measured together with $\Phi_{V D S S}$ by waveform fitting (Figs. 3 and 4). Whereas crustal thickness can be estimated from a single SsPmp observation with an assumed $V_{p}{ }^{a v}$, both $H_{V D S S}$ and $V_{p}^{a v}$ can be constrained using multiple events recorded at the same station (Fig. 5; Kang et al., 2016). The uncertainties of our $H_{V D S S}$ and $V_{p}{ }^{a v}$ measurements $(4.0 \mathrm{~km}$ and $0.20 \mathrm{~km} / \mathrm{s}$ respectively) at $\mathrm{YKW} 3$ are larger than those given by Kang et al., 2016 for two stations in Australia $(\sim 3.0 \mathrm{~km}$ and $\sim 0.15 \mathrm{~km} / \mathrm{s}$ respectively). Three factors might contribute to the higher uncertainties of our measurements. First, the uncertainty of our $T_{V D S S}(\sim 0.3 \mathrm{~s})$ is greater than Kang et al. $(\sim 0.18 \mathrm{~s})$. Second, the ray parameter range of our 
study $(0.1247-0.1327 \mathrm{~s} / \mathrm{km})$ is smaller than both cases in Kang et al. (0.1223-0.1349 s/km for FORT and 0.1226-0.1369 s/km for WB2). Third, the number of events used in our study (7) is smaller than both cases in Kang et al. 2016 (20 for Fort and 12 for WB2). For the first factor, we note that whereas we compute $T_{V D S S}$ uncertainties in a quantitative way (Supplementary Text 1), the uncertainties in Kang et al., 2016 are estimated empirically, making the $T_{V D S S}$ uncertainties in the two papers not directly comparable. For the second and third factor, we note that we apply a very strict criterion for our data, so that the quality of $\Phi_{V D S S}$, a less robust observable than $T_{V D S S}$, is guaranteed. Ideally, if only $T_{V D S S}$ is concerned, we could lower our standard to include more events with wider $p$ range, which might reduce the uncertainties of our estimated $H_{V D S S}$ and $V_{p}{ }^{a v}$ (Kang et al., 2016).

While inferring $V_{p}^{u m}, H_{V D S S}$ and $V_{p}^{a v}$ from $\Phi_{V D S S}$ and $T_{V D S S}$ observations, we implicitly assume the CMB to be a sharp boundary as opposed to a broad transition zone. When the CMB is a velocity-gradient zone thinner than the dominant wave-length of the incident $\mathrm{P}$ wave ( 25 $\mathrm{km}$ for typical field data), as we believe is true for most continental areas, $\Phi_{V D S S}$ is not significantly different from the case with a sharp CMB (Liu et al., 2018), thus our method of deriving $V_{p}^{u m}$ from $\Phi_{V D S S}$ still applies. When the CMB is a velocity-gradient zone with some of the $S s P m p$ rays turning in it (1/p in the range of the gradient zone), the $p$ - $T_{V D S S}$ relation (moveout) is different from the case with a sharp CMB (Liu et al., 2018), making our method of deriving $H$ and $V_{p}{ }^{a v}$ from $T_{V D S S}$ inaccurate. In such a case, if we know $V_{p}^{u m}$ either a priori or from $\Phi_{V D S S}$, we could use only $S S P m p$ with turning velocities higher than $V_{p}^{u m}\left(1 / p>V_{p}^{u m}\right)$, so that all the reflections happen at the bottom of the CMB. In this way, we effectively measure the average $V_{p}$ of the crust and the CMB.

The very good agreement between $H_{V D S S}$ and $H_{H k}$ (Fig. 6) for the SW Slave Province not only demonstrates the robustness of our method, but also verifies the underlying assumptions that we make about the study area. First, the study area is well approximated with a $1 \mathrm{D}$ crustal model. Second, the CMB beneath the study area is likely a sharp boundary, so that SsPmp reflections and $P S$ conversions happen at the same depth. Our PRF-VDSS joint analysis can constrain crustal average $V_{p} / V_{s}$ ratio using only Ps conversions from PRFs. Our method is a significant development for two reasons. First, unlike conventional $H-k$ stacking technique, our method does not require the presence of the Moho multiples (PpPms, PpSms etc.), which are not always robustly observed. Second, in addition to $k$, our method also gives $V_{p}{ }^{a v}$, which is an input 
parameter for conventional $H-k$ stacking technique. Although a formal estimation of $k_{H k}$ uncertainty is not obtained here, based on the amplitude distribution of our $H-k$ image, the uncertainty of $k_{H k}$ and $k_{\text {joint }}$ are likely similar (Fig. 6). As mentioned above, if we include more events with a wider $p$ range, the uncertainties of $H$ and $V_{p}{ }^{a v}$, hence $k_{\text {joint }}$, are likely to further decrease.

When comparing our results with the Lithoprobe active-source results in the same area, we find that whereas the reflection Moho depth $(\sim 37.5 \mathrm{~km}$; Hammer et al., 2010) agrees well with our results, the refraction Moho depth is significantly shallower ( $34 \mathrm{~km}$ in Hammer et al., 2010 and $31 \mathrm{~km}$ in Fernández-Viejo et al., 2005) than both our results and the reflection Moho (Fig. 9c). In addition, the crustal average $V_{p}$ and $V_{p} / V_{s}$ ratio derived from refraction experiments ( $\sim 6.4 \mathrm{~km} / \mathrm{s}$ and $\sim 1.69$ respectively; Fernández-Viejo et al., 2005) are both lower than our results $(6.61 \pm 0.26 \mathrm{~km} / \mathrm{s}$ and $1.747 \pm 0.08$ respectively). Fernández-Viejo et al., 2005 interpreted their low crustal average $V_{p}$ and $V_{p} / V_{s}$ ratio as an evidence for a felsic composition of the crust in the SW Slave Province, whereas our results indicate an intermediate average crustal composition (Fig. 8). Fernández-Viejo et al. explained a reginal Bouguer gravity low with their silicic but thin crust; our intermediate but thicker crust is an equally consistent alternative. A trend of increasing crustal average $V_{p}, V_{p} / V_{s}$ ratio and thickness with decreasing crustal age in the Western Australia Craton has been suggested to reflect a transition of crust-forming mechanism from plume tectonics to subduction-zone tectonics during Archean, which may also apply globally (Yuan, 2015). Within the framework of Yuan, 2015, our crustal average $V_{p}, V_{p} / V_{s}$ ratio and thickness are most consistent with a Neoarchean age. We note that a more comprehensive study of crustal property and geological records in the Slave Province is needed to confirm if the model of Yuan 2015 is applicable to this area.

\section{Conclusions}

We show with synthetic and field examples that $T_{V D S S}$ and $\Phi_{V D S S}$ can be used to estimate crustal average $V_{p}$, Moho depth and $V_{p}$ of the uppermost mantle. We also demonstrate that we can acquire independent measurements of crustal average $V_{p} / V_{s}$ ratio and composition with PRFVDSS joint analysis. Our field example from the SW Slave Province show an intermediate crustal composition, which indicates a Neoarchean crustal age. 
EarthArXiv preprint, in review with Geophysical Journal International

\section{Acknowledgements:}

Tianze Liu is supported by a Stanford Graduate Fellowship. Gabriel Ferragut was supported by an IRIS internship during his stay at Stanford. We thank Canadian Hazards Information Service for providing waveform data of the POLARIS array. We also thank Jieyuan Ning from Peking University for his valuable advices.

\section{References:}

Aki, K., Richards, P.G., 1980a. Phase shifts: phase delay and phase advance, in: Quantitative Seismology, Theory and Methods, Volume One. W. H. Freeman and Company, San Francisco, p. 156.

Aki, K., Richards, P.G., 1980b. Reflection and transmission of P-SV across a solid-solid interface, in: Quantitative Seismology, Theory and Methods, Volume One. W. H. Freeman and Company, San Francisco, pp. 144-151.

Bostock, M.G., 1998. Mantle stratigraphy and evolution of the Slave province. J. Geophys. Res. 103, 21183. doi:10.1029/98JB01069

Christensen, N.I., 1996. Poisson's ratio and crustal seismology. J. Geophys. Res. 101, 3139. doi:10.1029/95JB03446

Christensen, N.I., Mooney, W.D., 1995. Seismic velocity structure and composition of the continental crust: A global view. J. Geophys. Res. Solid Earth 100, 9761-9788. doi:10.1029/95JB00259

Cook, F.A., 2002. Fine structure of the continental reflection Moho. Bull. Geol. Soc. Am. 114, 64-79. doi:10.1130/0016-7606(2002)114<0064:FSOTCR >2.0.CO;2

Fernández-Viejo, G., Clowes, R.M., Welford, J.K., 2005. Constraints on the composition of the crust and uppermost mantle in northwestern Canada: $V p / V_{s}$ variations along Lithoprobe's SNorCLE transect. Can. J. Earth Sci. 42, 1205-1222. doi:10.1139/e05-028

Hammer, P.T.C., Clowes, R.M., Cook, F.A., van der Velden, A.J., Vasudevan, K., 2010. The Lithoprobe trans-continental lithospheric cross sections: imaging the internal structure of the North American continent. Can. J. Earth Sci. 47, 821-857. doi:10.1139/E10-036

Herrmann, R.B., 2013. Computer Programs in Seismology: An Evolving Tool for Instruction and Research. Seismol. Res. Lett. 84, 1081-1088. doi:10.1785/0220110096

Kang, D., Yu, C., Ning, J., Chen, W., 2016. Simultaneous Determination of Crustal Thickness 
EarthArXiv preprint, in review with Geophysical Journal International

and $P$ Wavespeed by Virtual Deep Seismic Sounding (VDSS). Seismol. Res. Lett. 87, 1104-1111. doi:10.1785/0220160056

Liu, T., Klemperer, S.L., Yu, C., Ning, J., 2018. Post-critical SsPmp and its applications to Virtual Deep Seismic Sounding (VDSS) - 1: sensitivity to lithospheric 1-D and 2-D structure. Geophys. J. Int. 215, 880-894. doi:10.1093/gji/ggy307

Parker, E.H., Hawman, R.B., Fischer, K.M., Wagner, L.S., 2016. Estimating crustal thickness using SsPmp in regions covered by low-velocity sediments: Imaging the Moho beneath the Southeastern Suture of the Appalachian Margin Experiment (SESAME) array, SE Atlantic Coastal Plain. Geophys. Res. Lett. 43, 9627-9635. doi:10.1002/2016GL070103

Porritt, R.W., Miller, M.S., 2018. Updates to FuncLab, a Matlab based GUI for handling receiver functions. Comput. Geosci. 111, 260-271. doi:10.1016/j.cageo.2017.11.022

Randall, G.E., 1989. Efficient calculation of differential seismograms for lithospheric receiver functions. Geophys. J. Int. 99, 469-481. doi:10.1111/j.1365-246X.1989.tb02033.x

Snyder, D., Bruneton, M., 2007. Seismic anisotropy of the Slave craton, NW Canada, from joint interpretation of SKS and Rayleigh waves. Geophys. J. Int. 169, 170-188. doi:10.1111/j.1365-246X.2006.03287.x

Tian, X., Chen, Y., Tseng, T.L., Klemperer, S.L., Thybo, H., Liu, Z., Xu, T., Liang, X., Bai, Z., Zhang, X., Si, S., Sun, C., Lan, H., Wang, E., Teng, J., 2015. Weakly coupled lithospheric extension in southern Tibet. Earth Planet. Sci. Lett. 430, 171-177. doi:10.1016/j.epsl.2015.08.025

Tseng, T.L., Chen, W.P., Nowack, R.L., 2009. Northward thinning of Tibetan crust revealed by virtual seismic profiles. Geophys. Res. Lett. 36, 1-5. doi:10.1029/2009GL040457

Yu, C., Chen, W.P., van der Hilst, R.D., 2016. Constraints on residual topography and crustal properties in the western United States from virtual deep seismic sounding. J. Geophys. Res. Solid Earth 121, 5917-5930. doi:10.1002/2016JB013046

Yu, C.Q., Chen, W.P., Ning, J.Y., Tao, K., Tseng, T.L., Fang, X.D., John Chen, Y., van der Hilst, R.D., 2012. Thick crust beneath the Ordos plateau: Implications for instability of the North China craton. Earth Planet. Sci. Lett. 357-358, 366-375. doi:10.1016/j.eps1.2012.09.027 Yu, C.Q., Chen, W.P., Van Der Hilst, R.D., 2013. Removing source-side scattering for virtual deep seismic sounding (VDSS). Geophys. J. Int. 195, 1932-1941. doi:10.1093/gji/ggt359

Zhu, L., Kanamori, H., 2000. Moho depth variation in southern California from teleseismic 
EarthArXiv preprint, in review with Geophysical Journal International

receiver functions. J. Geophys. Res. 105, 2969-2980. doi:Doi 10.1029/1999jb900322 
EarthArXiv preprint, in review with Geophysical Journal International

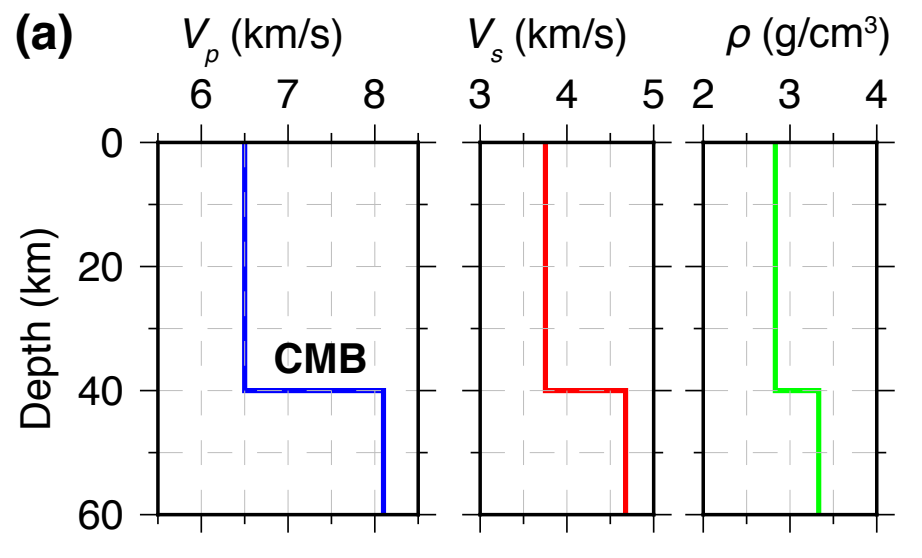

$V_{s}(\mathrm{~km} / \mathrm{s}) \quad \rho\left(\mathrm{g} / \mathrm{cm}^{3}\right)$

(b)

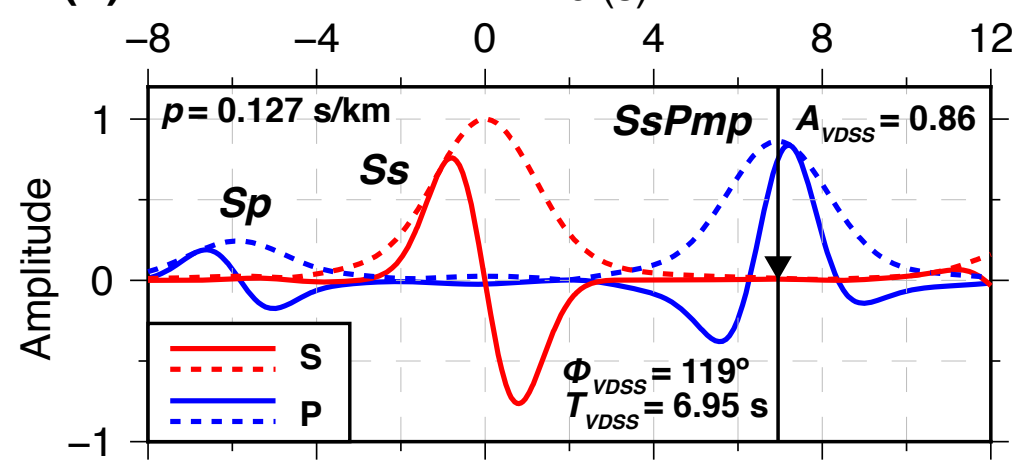

(c)

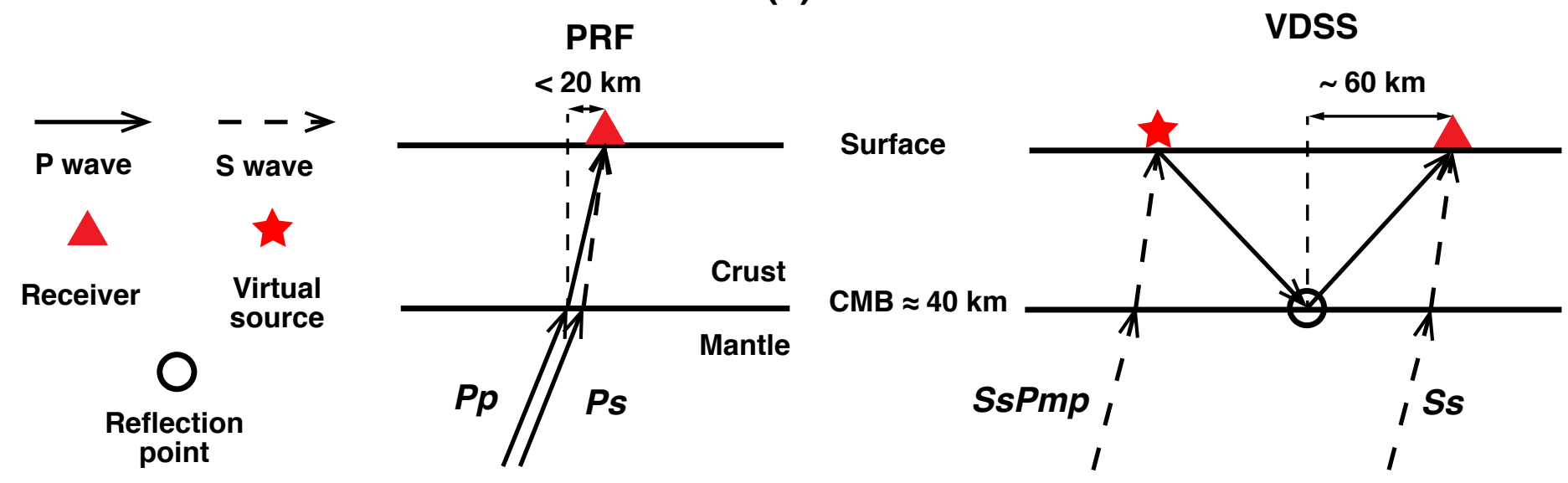


EarthArXiv preprint, in review with Geophysical Journal International

Figure 1. (a): 1D $V_{p}, V_{s}$ and density model ('Model \#1'). (b): P- and S-component synthetic seismograms ('observed waveforms') computed with Model \#1for a ray parameter $p=0.127 \mathrm{~s} / \mathrm{km}$ (epicentral distance of $\sim 48.5^{\circ}$ ). The dashed curves are corresponding envelope functions. Here and throughout this paper, P-component is blue and S-component is red. Note the high amplitude and large phase shift of $S s P m p$ relative to $S s$. (c): Comparison between ray paths of $\mathrm{P}$ receiver functions (PRF) and Virtual Deep Seismic Sounding (VDSS). 
EarthArXiv preprint, in review with Geophysical Journal International

(a)

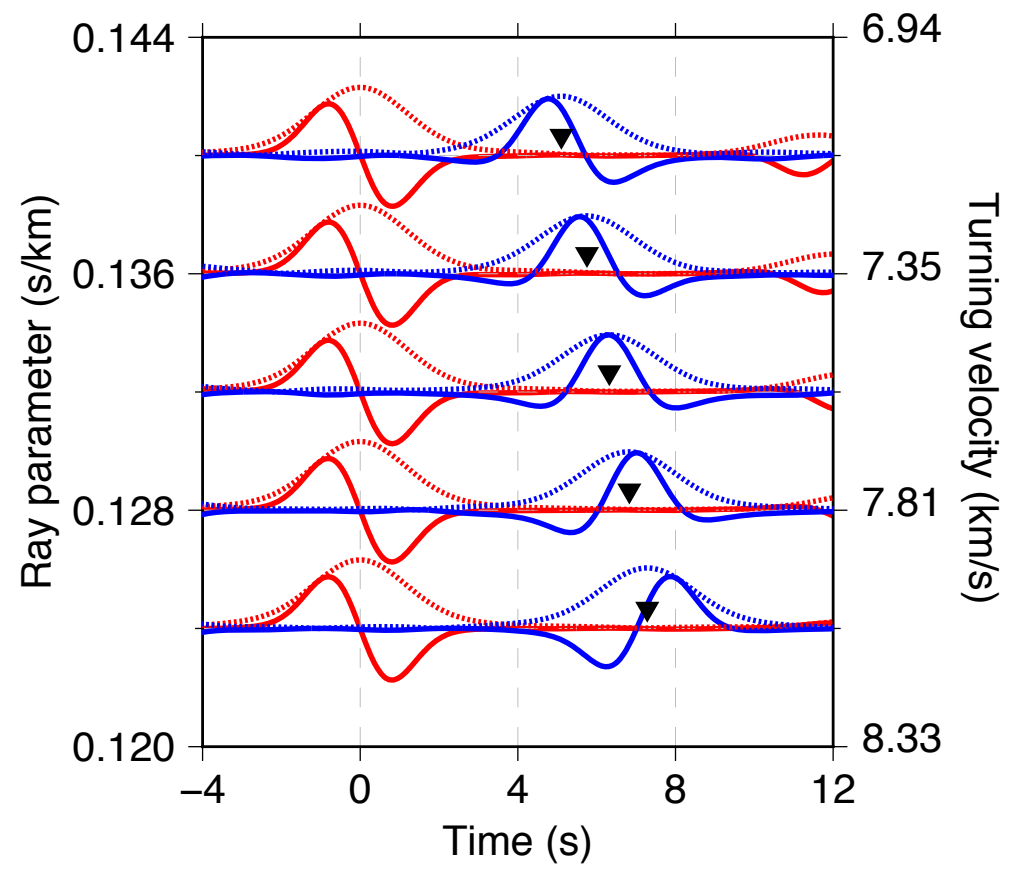

(b)

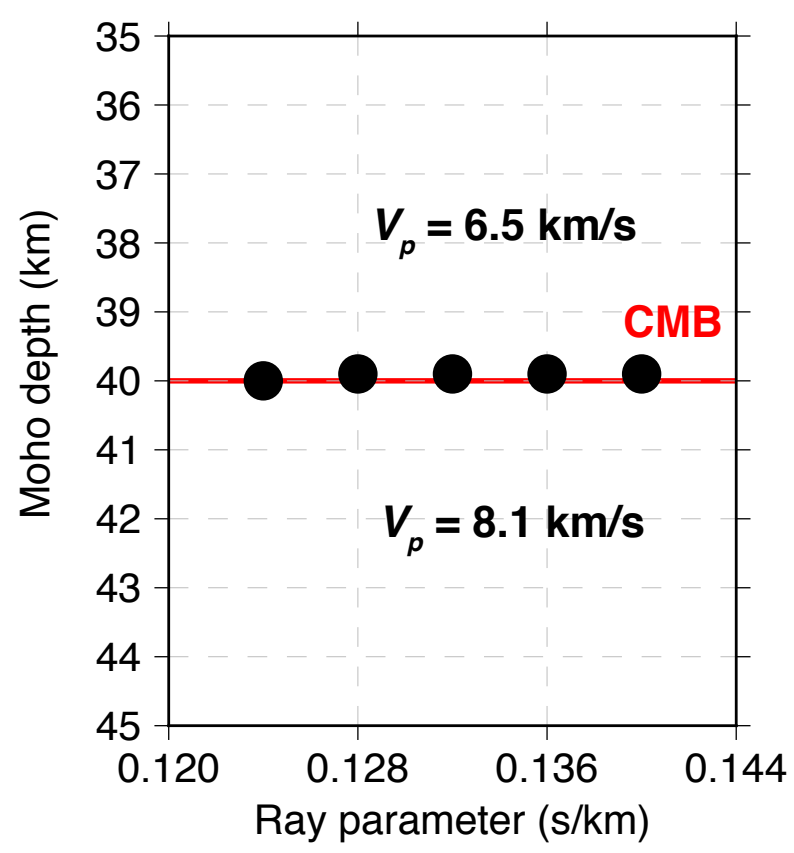


EarthArXiv preprint, in review with Geophysical Journal International

Figure 2. (a) Solid curves: P (blue) and S-component (red) synthetic waveforms ('observed waveforms') computed with Model \#1 for ray parameter $p=0.1240-$ $0.1400 \mathrm{~s} / \mathrm{km}$. Solid curves: blue is P- and red is S-component. Dotted curves: envelope functions. Black triangles: theoretical $T_{V D S S}$ computed for Model \#1, always located at the peak of the P-component envelope functions despite the change in $\Phi_{V D S S}$. (b) Black circles: Moho depths derived from $T_{V D S S}$ estimated by picking peaks on $\mathrm{P}$ envelope functions and converting to depth using the correct crustal average $V_{p}=6.5 \mathrm{~km} / \mathrm{s}$. Red line: true CMB depth at $40 \mathrm{~km}$. 
(a)

(b)

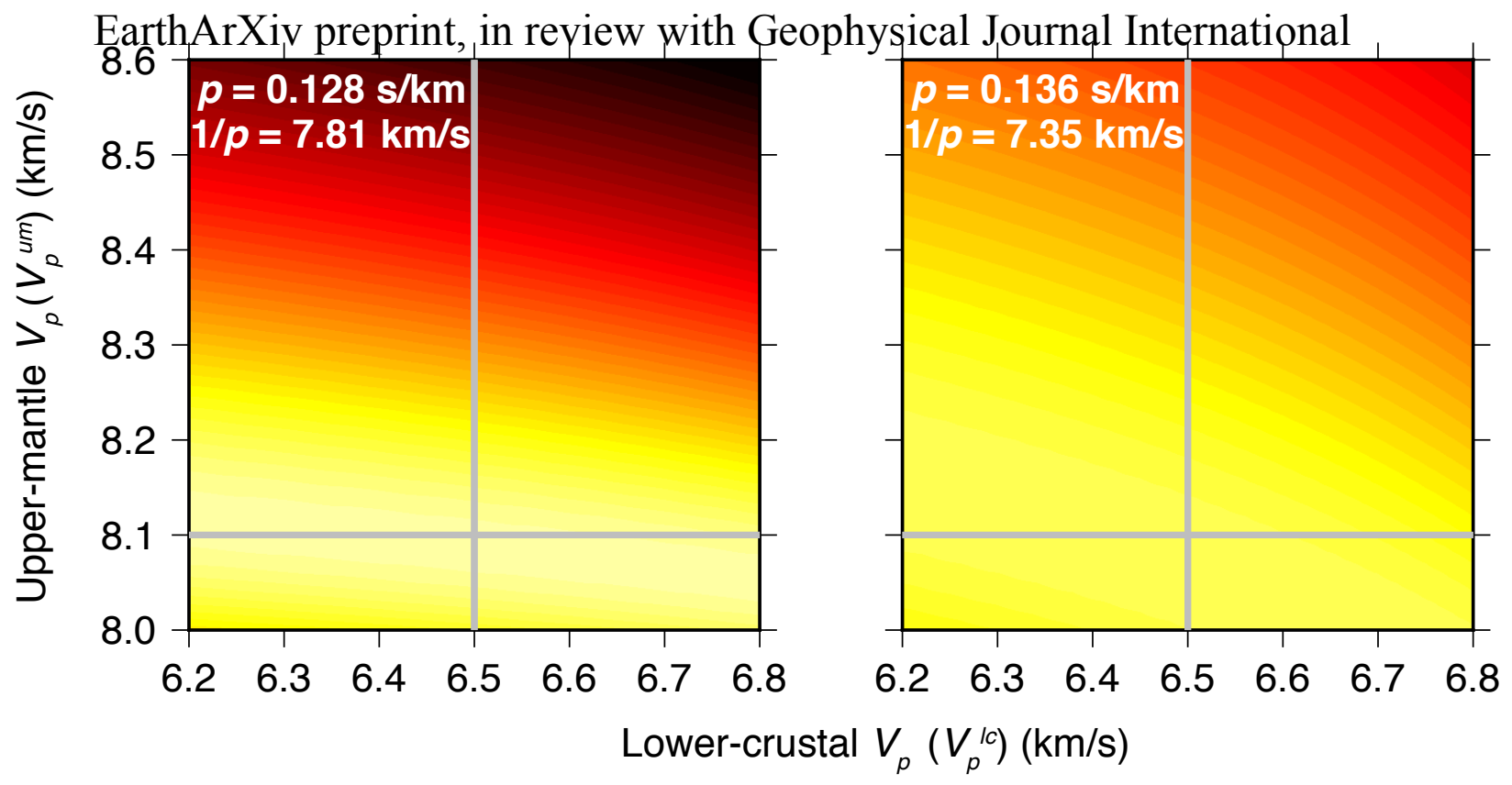

Misfit

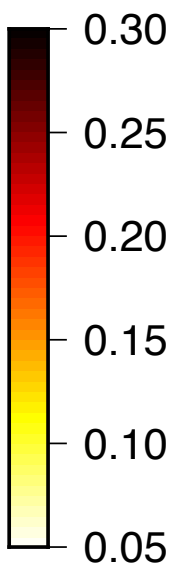


EarthArXiv preprint, in review with Geophysical Journal International

Figure 3. Normalized RMS misfit between synthetic waveforms generated with a grid search in $V_{p}^{u m}-V_{p}^{l c}$ space and 'observed waveform' computed with Model \#1 for (a) $p=0.128 \mathrm{~s} / \mathrm{km}$ and (b) $p=0.136 \mathrm{~s} / \mathrm{km}$. Misfit is calculated over a 14-s wide window around SsPmp. Best fit to the 'observed waveform' is always at the Model \#1 parameters (gray crosses), but $V_{p}^{u m}$ is most tightly constrained when the 'observed waveform' has $1 / p$ close to the true $V_{p}^{u m}$ (from Model \#1), i.e. far better for (a) $p=0.128 \mathrm{~s} / \mathrm{km}$ (see Fig. $4 \mathrm{~d}$ ) than for (b) $p=0.136 \mathrm{~s} / \mathrm{km}$ (see Fig. 4f). 
EarthArXiv preprint, in review with Geophysical Journal International
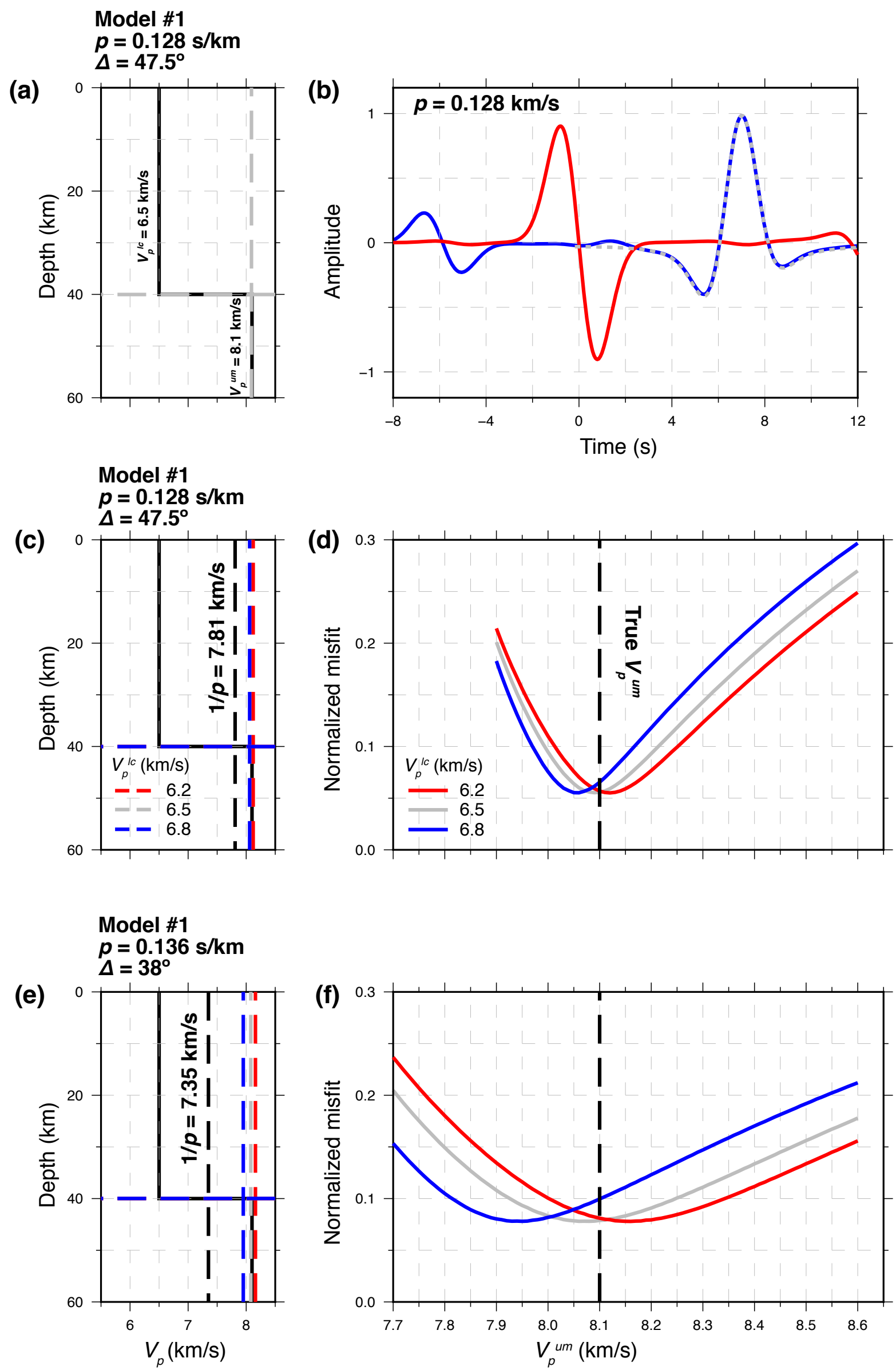
Figure 4. Modelling Moho depth and $V_{p}^{u m}$ from waveforms computed for Model\#1, with the additional constraint of an assumed $V_{p}^{l c}$. (a) and (b): modelling constrained using the correct $V_{p}^{l c}=6.5 \mathrm{~km} / \mathrm{s}$. (a): Gray dashed lines: Moho depth and $V_{p}^{u m}$ that best fit $T_{V D S S}$ and $\Phi_{V D S S}$, very closely matching Model \#1 (black line). A crustal average $V_{p}{ }^{a v}=6.5 \mathrm{~km} / \mathrm{s}$ is used to convert $T_{V D S S}$ to Moho depth. (b): blue and red curves: synthetic $\mathrm{P}$ and $\mathrm{S}$ waveforms computed for Model \#1 and $p=$ $0.128 \mathrm{~s} / \mathrm{km}$ ('observations'). Gray dashed curve: P-component $S s P m p$ waveform that best fits $T_{V D S S}$ and $\Phi_{V D S S}$. (c-f): A comparison of models using different assumed $V_{p}^{l c}$. (c) and (e): Model \#1 as in (a) with Moho depths and $V_{p}^{u m}$ estimated for assumed $V_{p}^{l c}=6.2$ (red), 6.5 (grey) and 6.6 (blue) $\mathrm{km} / \mathrm{s}$, for $p=0.128$ and 0.136 $\mathrm{s} / \mathrm{km}$ respectively. (d) and (f): Normalized misfits as functions of $V_{p}^{u m}$ for each case. Note the choice of $V_{p}^{l c}$ has little effect on estimated $V_{p}^{u m}$ when $p$ is small $(1 / p$ is large and close to $\left.V_{p}^{u m} ; 4 \mathrm{f}\right)$, but has a significant effect when $p$ is large $(1 / p$ is small and far from $\left.V_{p}^{u m} ; 4 \mathrm{~g}\right)$. 
(a)

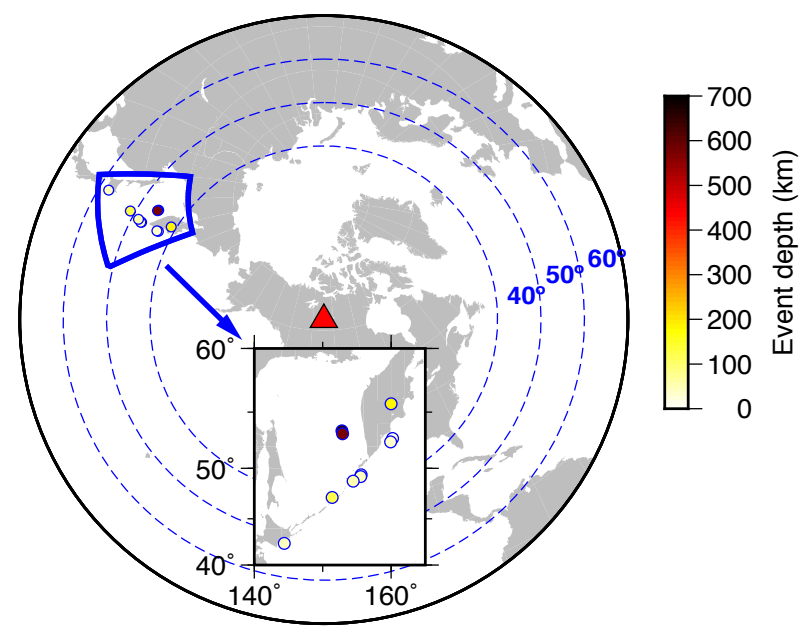

(c)

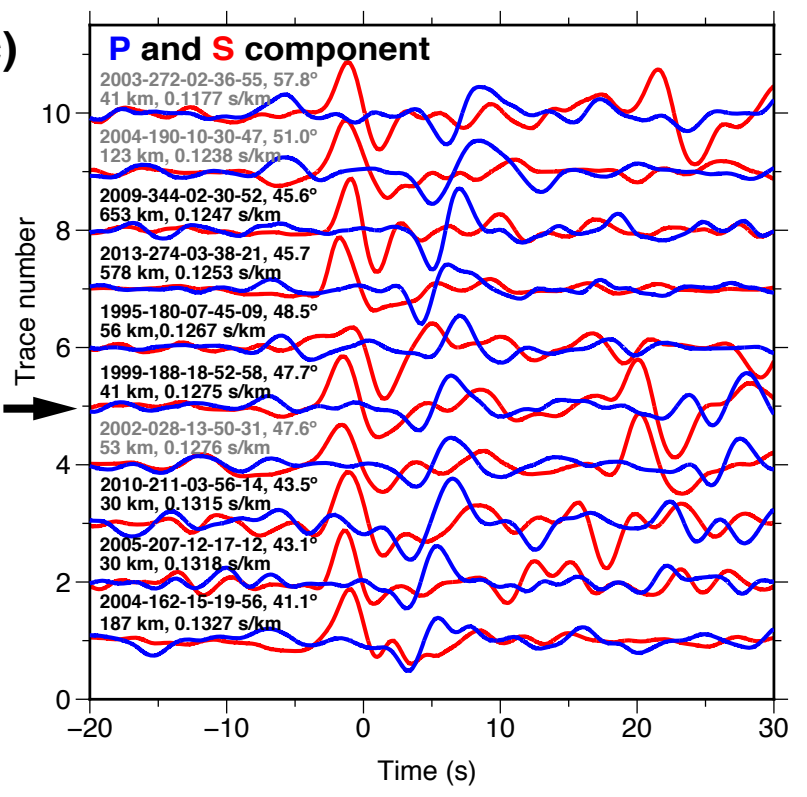

(e)

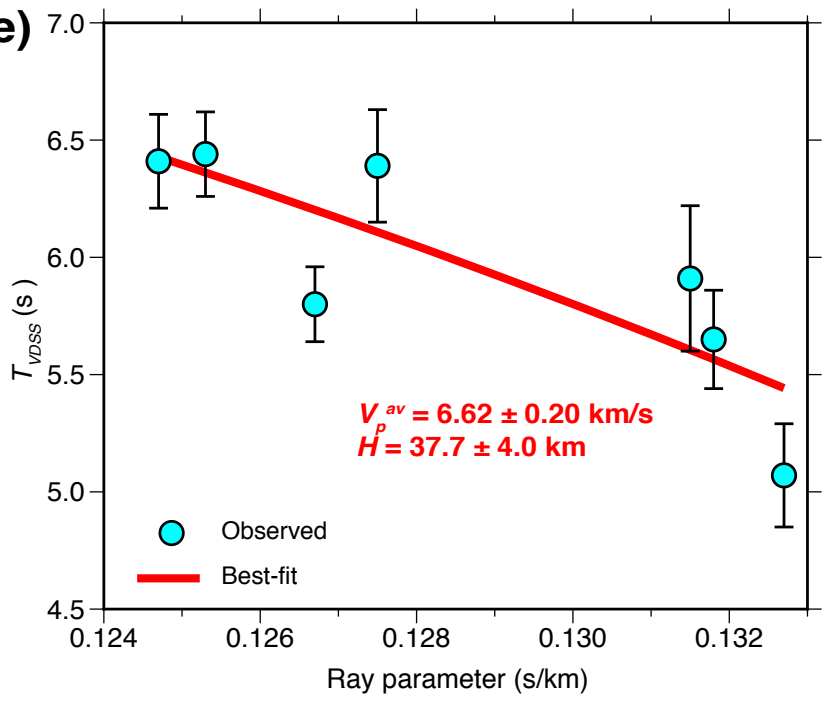

(b)

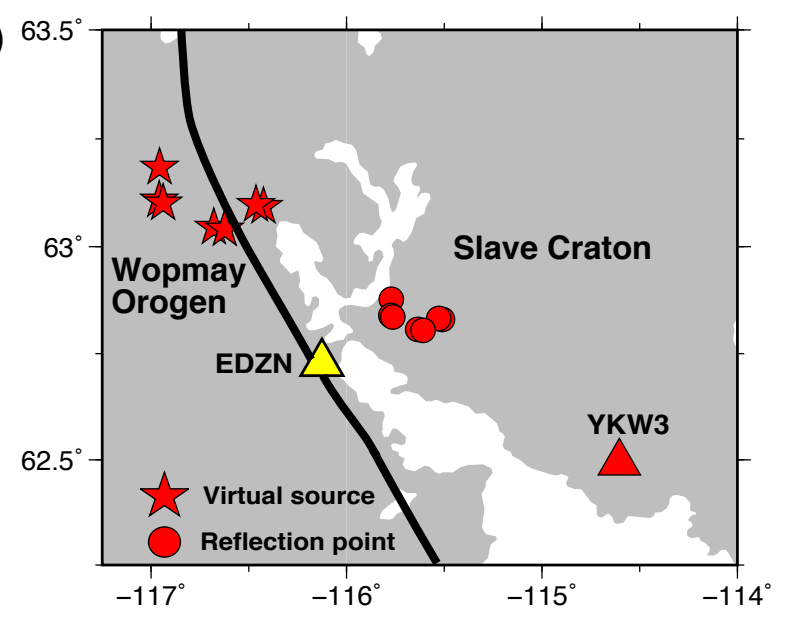

(d)

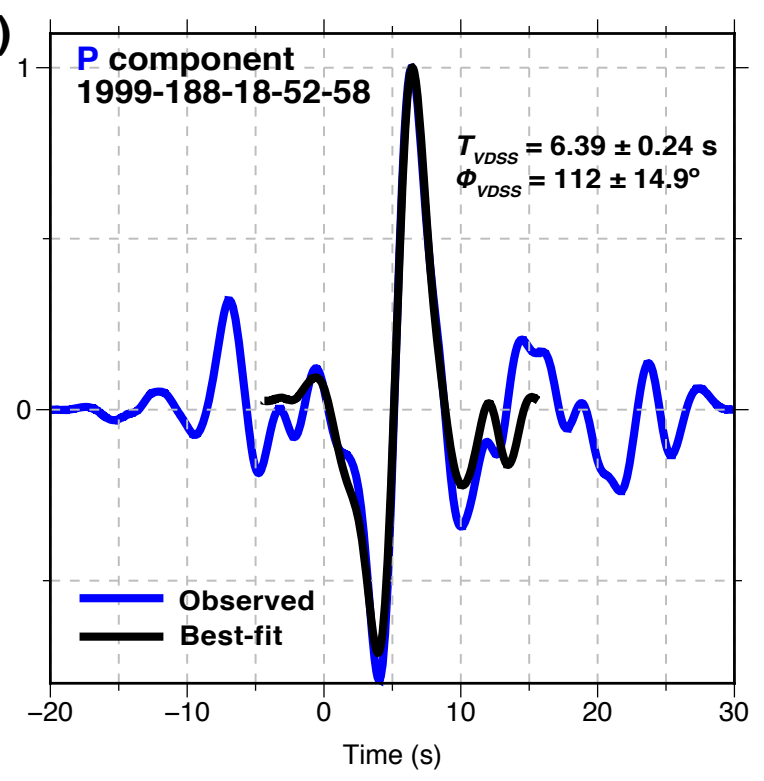

(f)

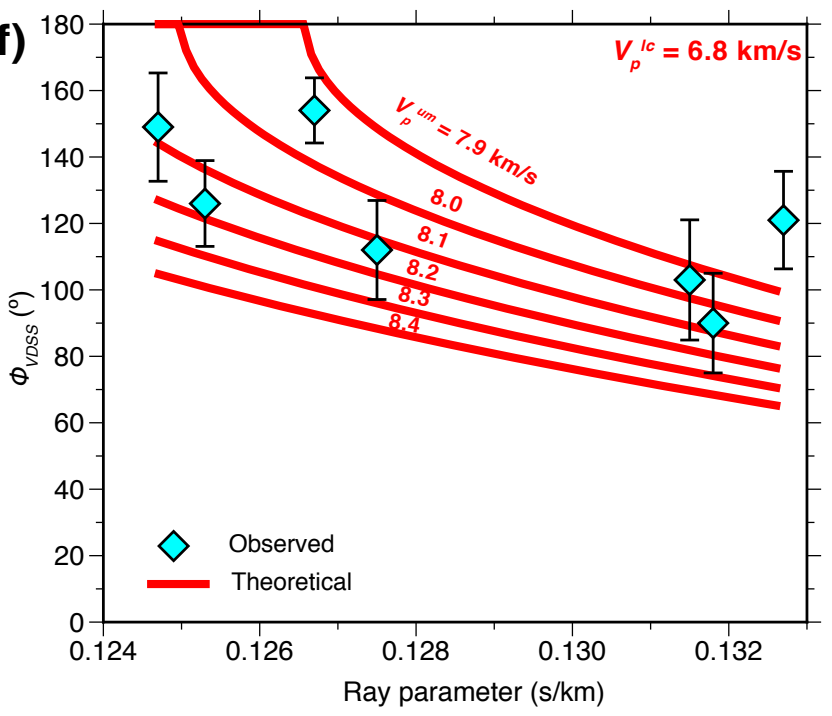


Figure 5. $V_{p}^{u m}, V_{p}^{a v}$ and Moho depth $H$ near station YKW3 derived from $T_{V D S S}$ and $\Phi_{\text {VDSS. }}$ (a): Station YKW3 and ten earthquakes with back-azimuth 297-304 ${ }^{\circ}, \mathrm{Mw}>$ 5.5, distance $40-60^{\circ}$ and depth $30-700 \mathrm{~km}$, colored by their focal depth. (b): Locations of stations (YKW3 and EDZN), Moho reflection points and virtual sources. The reflection-point and virtual-source locations are computed for the seven out of ten events in (a) with acceptable waveform misfits (see (c)) using the best-fit $V_{p}^{a v}$ and $H$ (see (e)). The RF results of EDZN are shown in Fig. 7. (c): P and $\mathrm{S}$ component waveforms of the earthquakes used. The traces are sorted by their ray parameters (large to small) and labeled with their origin time, epicentral distance (in ${ }^{\circ}$ ), focal depth and ray parameter. Three traces with gray labels have high misfit and are not used in $T_{V D S S}$ and $\Phi_{V D S S}$ analysis or shown in (b). Black arrow marks the event shown in (d). (d): Observed and best-fit P-component waveforms of Event 1999-188-18-52-58. (e): Observed $T_{V D S S}$ as function of ray parameter (cyan circle), and best-fit relationship of $V_{p}^{a v}$ and $H$ (red line) from linear regression (Kang et al., 2016.) (f): Observed $\Phi_{V D S S}$ as function of ray parameter (cyan diamond), and theoretical relations between $\Phi_{V D S S}$ and ray parameter for variable $V_{p}^{u m}$ (red curves) but $V_{p}^{l c}$ fixed at $6.8 \mathrm{~km} / \mathrm{s}$. Observed $\Phi_{V D S S}$ favors $V_{p}^{u m} \sim 8.0-8.1 \mathrm{~km} / \mathrm{s}$. 
EarthArXiv preprint, in review with Geophysical Journal International
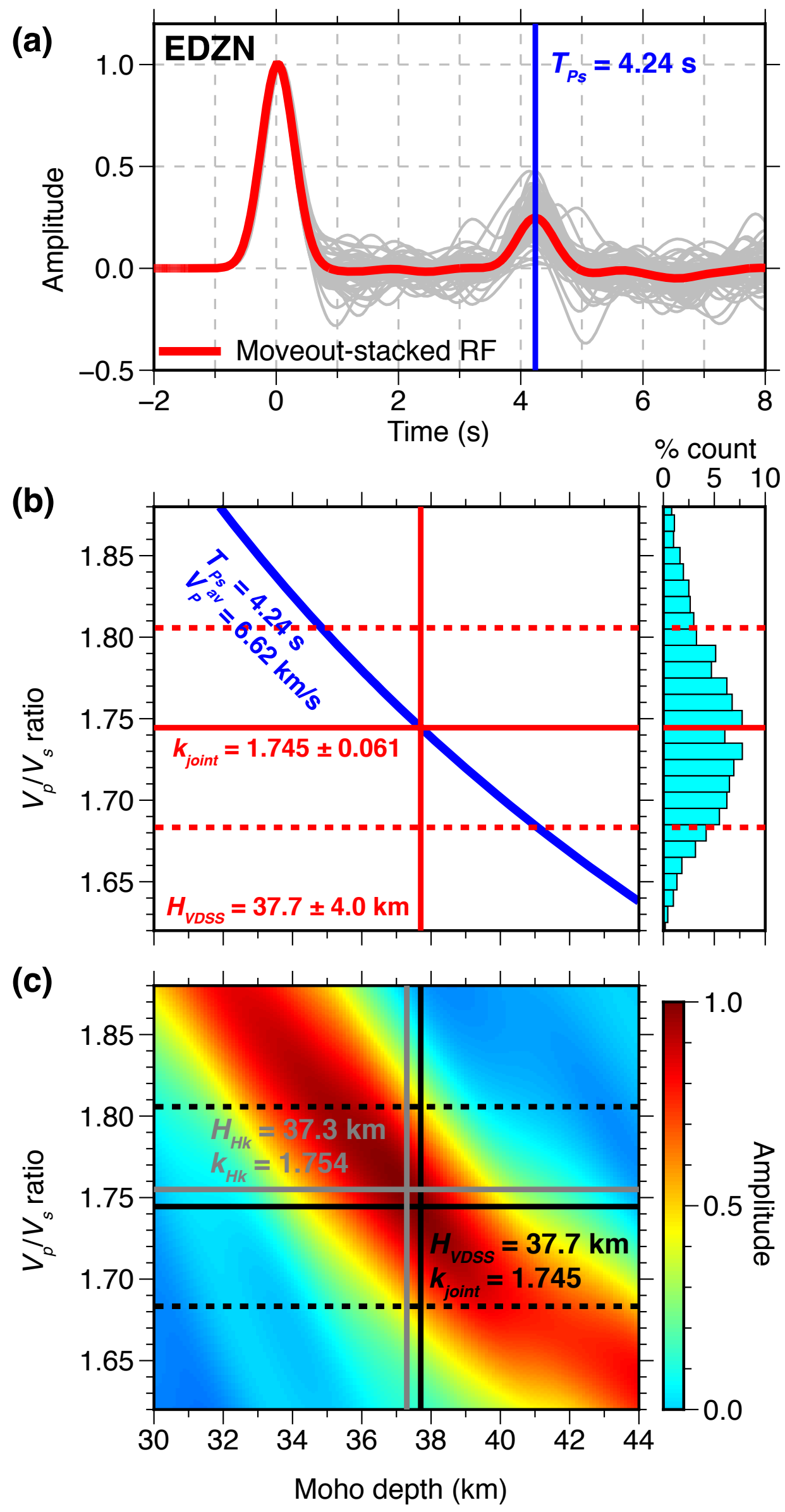
Figure 6. PRF-VDSS joint analysis for crustal structure of SW Slave Province. (a): RF waveforms of EDZN. The stacked PRF is computed by summing 73 PRFs (gray curves) moveout-corrected to normal incidence. (b): Determination of crustal average $V_{p} / V_{s}$ ratio $\left(k_{j o i n t}\right)$ from PRF $T_{P S}$ and VDSS Moho depth $\left(H_{V D S S}\right)$ and crustal average $V_{p}\left(V_{p}^{a v}\right)$. The dashed gray lines mark the estimated uncertainty of $k_{\text {joint }}$, which is computed by taking the standard deviation of 5000 random simulations of $k_{\text {joint }}$ (cyan histogram). (c): Comparison between $H_{V D S S}$ and $k_{\text {joint }}$ and $H$ and $k$ derived from conventional $H-k$ stacking $\left(H_{H k}\right.$ and $\left.k_{H k}\right)$. Background color is normalized amplitude of the conventional $H-k$ stack computed with $V_{p}{ }^{a v}=6.62$ $\mathrm{km} / \mathrm{s}$ and phase weight ratios $w_{P s}: w_{P p P m s}: w_{P p S m s}=1: 0.5: 0.5$. Note the close match between the two methods $(<1 \%$ difference $)$. 
EarthArXiv preprint, in review with Geophysical Journal International

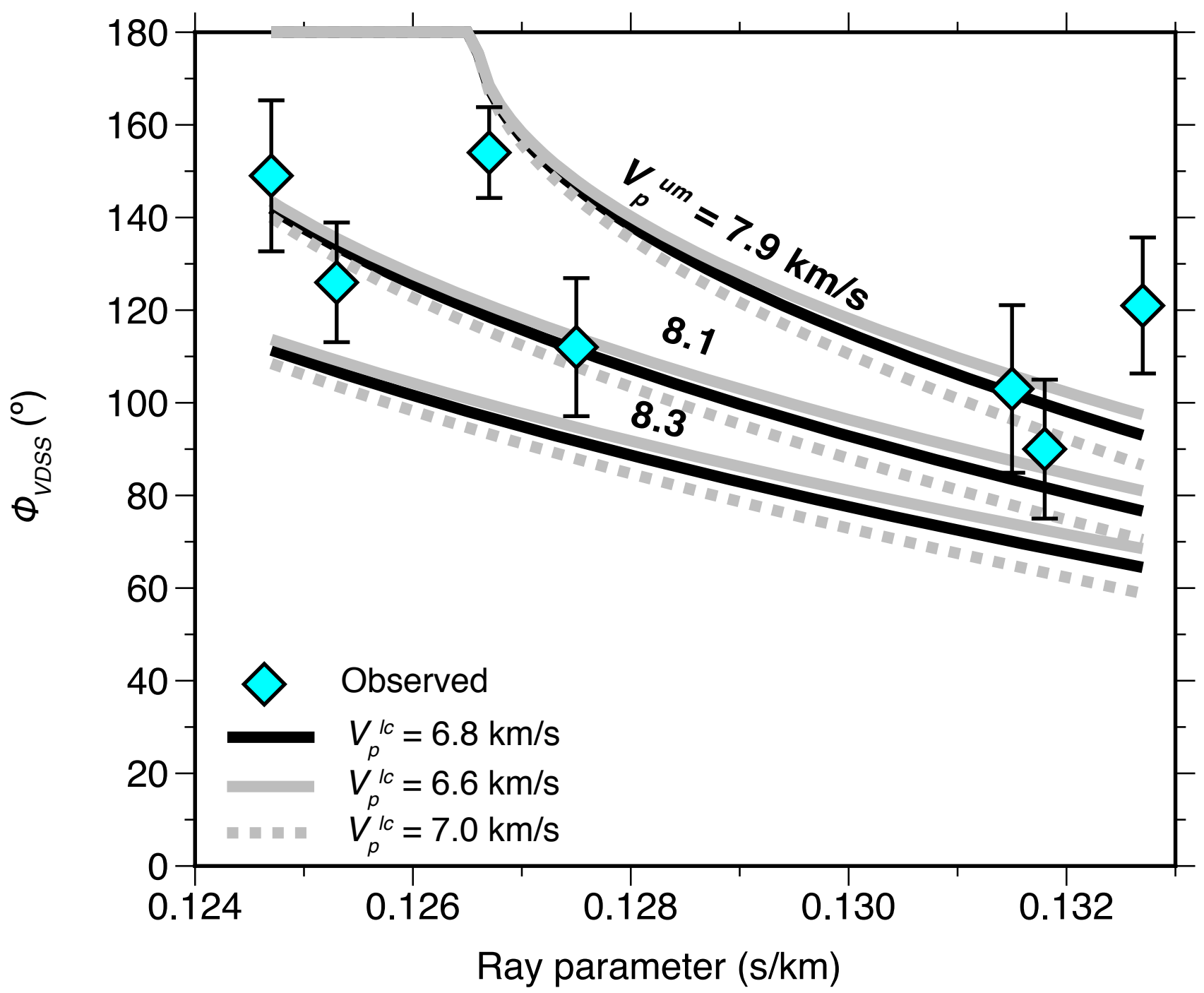


EarthArXiv preprint, in review with Geophysical Journal International

Figure 7. Effects of assumed $V_{p}^{l c}$ on $V_{p}^{u m}$ derived from observed $\Phi_{V D S S}$ as a function of ray parameter. The black curves and data points are the same as the ones in Fig. $5(\mathrm{f})$. 
EarthArXiv preprint, in review with Geophysical Journal International

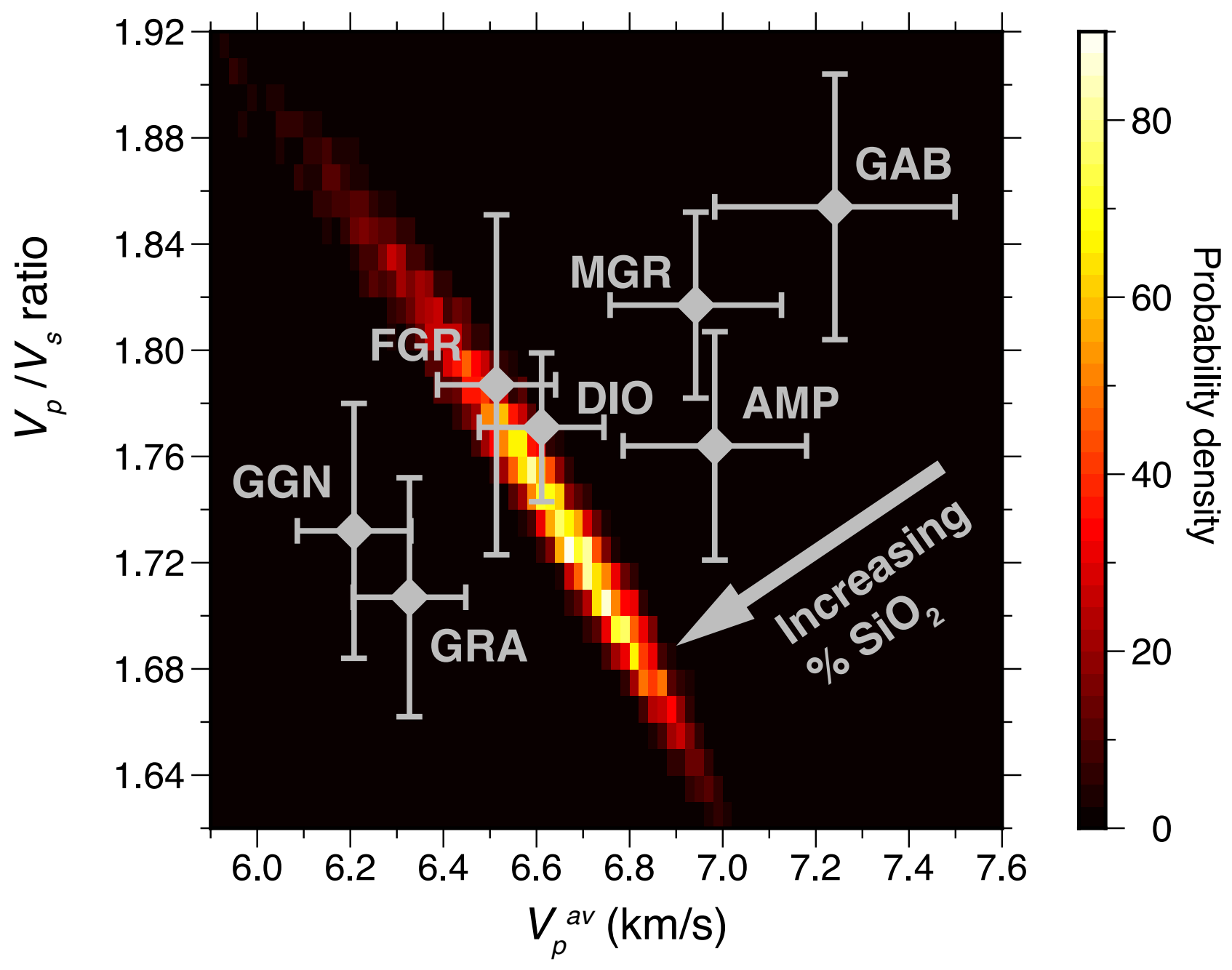


EarthArXiv preprint, in review with Geophysical Journal International

Figure 8. Constraining crustal average composition with RF-VDSS joint analysis. The probability density function is derived from 5000 random simulations of $V_{p}{ }^{a v}$ and $V_{p} / V_{s}$ ratio. The gray markers with error bars are measurements at $600 \mathrm{MPa}$ and room temperature from Christensen 1996. GAB: Gabbro-norite-troctolite; MGR: Mafic granulite; DIO: Diorite; FGR: Felsic granulite; GGN: Granite gneiss; GRA: Granite-granodiorite; AMP: Amphibolite. Note a dioritic average composition matches our seismic observations best. 
EarthArXiv preprint, in review with Geophysical Journal International

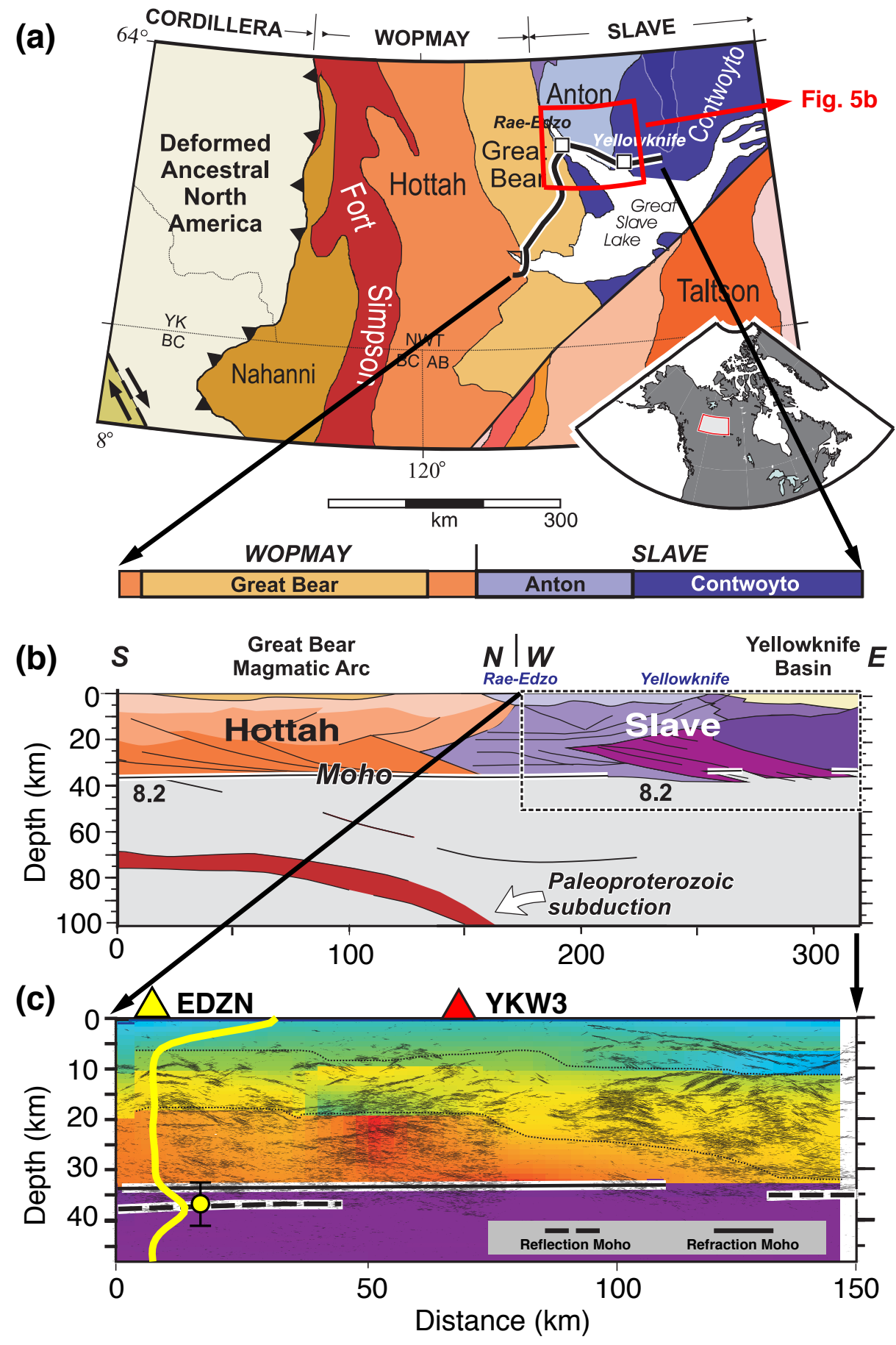

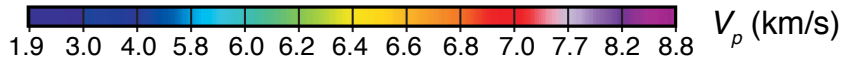


Figure 9. Summary of VDSS, PRF, and the Lithoprobe active-source results in the SW Slave Province (reproduced from Hammer et al., 2010). (a): Map showing the Lithoprobe profiles Line 1 (solid line) on a simplified tectonic map of NW Canada. (b): Simplified interpretation based on the reflection and refraction results in (c). The bar at the top shows the geologic terranes along the profile. (c): Comparison between our VDSS and PRF and Lithoprobe reflection and refraction results. The migrated reflection image is overlain on the refraction $V_{p}$ model. Yellow circle with error bars: VDSS Moho plotted at the reflection point. Yellow curve: moveout-stacked PRF mapped to depth domain and plotted at EDZN. Note that the VDSS, PRF and reflection Moho depths agree with each other $(\sim 37.5 \mathrm{~km})$, whereas the refraction Moho $(\sim 34 \mathrm{~km})$ is significantly shallower than them. 